\title{
UMA ANÁLISE CRÍTICA DA EVOLUÇÃO DAS DESPESAS FEDERAIS E DOS RESULTADOS EM EDUCAÇÃO NO BRASIL (2008-2017)
}

\author{
A CRITICAL ANALYSIS OF THE EVOLUTION OF FEDERAL \\ EXPENDITURES AND RESULTS IN EDUCATION IN BRAZIL (2008-2017)
}

José Querino Tavares Neto ${ }^{1}$

$\mathrm{UFG}$

Nilson Elias de Carvalho Junior ${ }^{2}$

$\mathrm{UFG}$

\begin{abstract}
Resumo
Indicadores dos gastos em educação num determinado período são um instrumento de grande relevância na compreensão dos problemas sociais que mereçam maior atenção e exijam definição de políticas públicas mais eficazes, correção de distorções e, consequentemente, redução de desigualdades. Partindo desse pressuposto, o presente trabalho apresenta dados da série histórica do gasto público educacional da União entre os anos de 2008 a 2017 e analisa o papel do governo federal no financiamento da educação, avaliando as despesas públicas realizadas no período e apresentando a necessidade de reorientação de gastos ineficientes. Para fundamentar tais análises, serão utilizados dados do Anuário da Educação Básica 2018, da Secretaria do Tesouro Nacional e da Receita Federal, mostrando a relação entre gastos educacionais e evolução da carga tributária, bem como os impactos da Emenda Constitucional no 95/2016 na destinação de recursos para a educação. Serão apresentados também dados do Programa Internacional de Avaliação de Alunos (PISA) e de relatórios de entidades internacionais, como a Organização para Cooperação e Desenvolvimento Econômico (OCDE) e o Banco Mundial, para assim ser feita uma comparação da eficiência dos investimentos na educação brasileira com a de outros países.
\end{abstract}

Palavras-chave

Educação. Financiamento público. Orçamento. Despesas públicas. Ineficiência administrativa.

\begin{abstract}
Indicators of spending on education in a given period are an instrument of great relevance in understanding the social problems that deserve greater attention and require definition of more effective public policies, correction of distortions and, consequently, result in reduction of inequalities. Based on this assumption, this paper presents data from the historical series of public educational expenditures of the Federal Union between 2008 and 2017 and analyzes the role of the federal government in the financing of education, evaluating the public expenditures during the period and presenting the need for reorientation of inefficient expenses. To base these analyzes, data from the Basic Education Yearbook 2018, from the National Treasury and the Federal Revenue Secretariat, will be used, showing the relationship between educational expenses and evolution of the tax burden, as well as the impacts of the Constitutional Amendment on the 95/2016 in the destination resources for education. The International Student Assessment Program (PISA) and reports from international organizations, such as the Organization for Economic Co-operation and Development (OECD) and the World Bank, will also be presented to compare the efficiency of investments in education with the expenses of other countries.
\end{abstract}

Keywords

Education. Public financing. Budget. Public expenditure. Administrative inefficiency.

\footnotetext{
1 Pós-doutorado em Direito Constitucional pela Universidade de Coimbra. Graduado em Ciências Sociais e em Direito. Mestre em Sociologia pela Universidade Estadual de Campinas. Doutor em Sociologia pela Universidade Estadual Paulista Júlio de Mesquita Filho - UNESP. Doutor em Direito pela Pontifícia Universidade Católica do Paraná. Professor Associado da Faculdade de Direito da Universidade Federal de Goiás, Professor do Programa em Direito e Políticas Públicas da UFG. Bolsista de Produtividade do CNPq. Orcid: 0000-0003-2496-4886.

2 Bacharel em Direito pela Universidade Federal de Goiás (UFG), e no Curso Superior de Tecnologia em Redes de Comunicação pelo Instituto Federal de Goiás (IFG). Mestrando em Direito e Políticas Públicas na Universidade Federal de Goiás (UFG). Especialista em Gestão Pública pela FABEC-GO e em Direito Administrativo e Licitações pelo Instituto Prominas.
} 
Revista da Faculdade Mineira de Direito | V.23 N.45 |

\section{INTRODUÇÃO}

O Brasil é um dos países que apresenta maiores níveis de desigualdade no mundo. Segundo Relatório da Organização para a Cooperação e Desenvolvimento Económico (OCDE, 2018), metade da população tem acesso a apenas 10\% da renda do país, enquanto os outros 90\% ficam nas mãos da outra metade.

A desigualdade no acesso à educação é um fenômeno que pode ser compreendido por meio da análise do direcionamento do gasto público em educação, que é um tipo de investimento que pode, a depender da forma em que for feito, contribuir para a ampliação ou para a redução de desigualdades. Isso porque num cenário de profundas distorções de distribuição de renda, o acesso à educação se se torna uma das poucas oportunidades de ascensão social daqueles que estão na base da pirâmide da sociedade. Assim, de nada adianta o aumento do Produto Interno Bruto (PIB) do país se esse crescimento não for inclusivo e não promover avanços no bem-estar da maioria da população.

Nesse sentido, é primordial que o Estado exerça seu papel de ampliar as oportunidades de acesso ao ensino em todos os níveis e, mais que isso, se comprometa na melhoria da qualidade do ensino, para que assim seja possibilitado aos jovens das camadas mais pobres da população mínimas condições de se qualificarem.

E é sobre esse problema que se debruça o presente artigo: o da análise do gasto público em educação para, com base nos dados obtidos, avaliar como esses gastos tem interferido no aumento ou na redução das distorções sociais.

Assim, o objetivo deste artigo é, partindo da compreensão da ampliação do acesso educação como instrumento de redução de desigualdades, analisar criticamente o papel da União no financiamento e a evolução das despesas do governo federal em educação, entre os anos de 2008 a 2017, com base em dados da Secretaria do Tesouro Nacional (STN) e em relatórios da Organização para a Cooperação e Desenvolvimento Econômico (OCDE), bem como em outros relatórios que apresentem dados relevantes sobre a evolução das despesas educacionais deste período. Desse modo, será possível analisar como se deu o financiamento das políticas públicas educacionais durante os três mandatos presidenciais do período e posteriormente elaborar conclusões diante dos dados obtidos.

Para tanto, será discutida a importância da formulação de políticas públicas adequadas na educação, incluindo a reorientação de gastos ineficientes, mostrando as principais alterações 
Revista da Faculdade Mineira de Direito |V.23 N.45 |

ocorridas nos investimentos federais no período em análise e apontar medidas que contribuam ao debate sobre o padrão dos gastos governamentais no sistema educacional.

\section{O PAPEL DA UNIÃO NO FINANCIAMENTO DA EDUCAÇÃo}

A Constituição Federal de 1988 estabeleceu uma descentralizada política de financiamento da educação, sendo previsto no artigo 211 que os sistemas de ensino seriam organizados em regime de colaboração entre todos os entes federativos, tendo como objetivo assegurar a universalização do ensino obrigatório.

Nesse sentido, o texto constitucional atribuiu aos Municípios a atuação prioritária no ensino fundamental e na educação infantil e, aos Estados, uma predominância de atuação nos ensinos fundamental e médio. Para ambos foi estabelecida, no artigo 212, a obrigatoriedade de aplicação anual de no mínimo $25 \%$ das receitas dos impostos arrecadados na manutenção e no desenvolvimento do ensino, enquanto da União foi exigida aplicação mínima de $18 \%$ de suas receitas na educação.

Originalmente, o $\int 1^{\circ}$ do artigo 211 da Constituição previa que à União caberia o atendimento prioritário à escolaridade obrigatória. Todavia, com a promulgação da Emenda Constitucional $n^{\circ} 14 / 1996$, a redação desse parágrafo foi revista e a União foi eximida desta responsabilidade, de modo que tal dispositivo passou a dispor apenas que a União organizaria o sistema federal de ensino e dos Territórios e visaria promover a equalização de oportunidades educacionais e padrão mínimo de qualidade do ensino mediante assistência técnica e financeira aos estados, ao Distrito Federal e aos municípios.

Assim, no regime de financiamento da educação, a União passou a possuir competências supletivas e redistributivas, que se manifestaram principalmente através do Fundo de Manutenção e Desenvolvimento da Educação Básica e de Valorização dos Profissionais da Educação (Fundeb), fundo de natureza contábil que distribui recursos aos demais entes da federação na proporção do número de alunos matriculados na educação básica e com o fim de serem aplicados desde a educação básica ao ensino médio e reduzir desigualdades no financiamento da educação. Esse fundo possui uma destacada função redistributiva, visto que é a principal fonte de recursos financeiros para a educação básica, e assume um papel de grande relevância em municípios menores, cujos orçamentos possuem dependência ainda maior dos recursos do referido fundo.

Outro mecanismo de financiamento - esse de caráter supletivo - é o Fundo Nacional de Desenvolvimento da Educação. Criado na forma de autarquia federal pela Lei no 5.537 , de 21 de 
Revista da Faculdade Mineira de Direito |V.23 N.45|

novembro de 1968, esse fundo é responsável pela execução de políticas educacionais, instrumentalizado por meio de transferências realizadas pelo Ministério da Educação, destinadas ao custeio básico das escolas, livros didáticos, alimentação e transporte de alunos (TESOURO NACIONAL, 2018).

Entretanto, apesar da relevante função destes fundos para a o desenvolvimento da educação básica, nos últimos quinze anos houve um aumento ainda mais destacado da participação da União no financiamento do ensino superior. Como relata Maria Paula Dallari Bucci e Paula Branco de Mello (2013), passou-se no país de 4,2 milhões de matrículas em 2004 para 6,7 milhões em 2011, havendo um acréscimo de 2,5 milhões de novos estudantes em cursos superiores. Segundo tais autoras, apesar dos números estarem distantes de países desenvolvidos, esse acréscimo demonstra uma alteração profunda na composição do alunado superior no Brasil, hoje muito mais diversa e democrática do ponto de vista socioeconômico, com oportunidades reais a muitos jovens (BUCCI; MELLO, 2013).

Entretanto, apesar dos números impressionarem, é preciso analisar se a forma em que os recursos foram distribuídos, através do Fundeb e do aumento dos investimentos diretos da União no ensino superior, promoveram ou não efetivas melhorias no sistema de financiamento da educação brasileira como um todo.

\section{ANÁLISE DOS GASTOS EM EDUCAÇÃO NO PERÍODO 2008-2017}

De acordo com levantamento “Aspectos Fiscais da Educação no Brasil” (TESOURO NACIONAL, 2018), elaborado pela Secretaria do Tesouro Nacional, houve um sensível crescimento dos investimentos em educação no período de 2008 à 2017, guardando relativa proporção com o crescimento do Produto Interno Bruto (PIB) do país, na esteira do que ordena a Constituição Federal ${ }^{3}$.

A tabela a seguir apresenta um resumo dos gastos em educação da União entre os anos de 2008 em 2017, trazendo a evolução do gasto primário total, evidenciando como esse montante foi subdivido entre os níveis de ensino e a proporção dos gastos educacionais tanto em relação à receita corrente total da União como em comparação ao Produto Interno do país no período.

\footnotetext{
3 Art. 214. A lei estabelecerá o plano nacional de educação, de duração decenal, com o objetivo de articular o sistema nacional de educação em regime de colaboração e definir diretrizes, objetivos, metas e estratégias de implementação para assegurar a manutenção e desenvolvimento do ensino em seus diversos níveis, etapas e modalidades por meio de ações integradas dos poderes públicos das diferentes esferas federativas que conduzam a: (Redação dada pela Emenda Constitucional no 59, de 2009) [...]

VI - estabelecimento de meta de aplicação de recursos públicos em educação como proporção do produto interno bruto. (Incluído pela Emenda Constitucional no 59, de 2009)
} 
Revista da Faculdade Mineira de Direito |V.23 N.45|

Tabela 1

Gasto em educação 2008-2017 (R\$ bilhões constantes de 2017).

\begin{tabular}{|c|c|c|c|c|c|c|c|c|c|c|}
\hline & 2008 & 2009 & 2010 & 2011 & 2012 & 2013 & 2014 & 2015 & 2016 & 2017 \\
\hline Educação & 61,4 & 71,0 & 90,0 & 98,7 & 112,5 & 119,2 & 130,2 & 127,0 & 123,6 & 117,2 \\
\hline tal & 3 & 3 & 4 & 51,4 & 58,1 & 69,4 & 0 & 1 & ,3 & 54 \\
\hline Edu & 18,9 & 23,6 & 26,6 & 3. & 37,2 & 38,3 & 39,1 & 38,9 & 37,4 & 34,6 \\
\hline & & & 170 & & & & 1 & 9 , & 9,0 & 7,2 \\
\hline ta Corrente - & 75 & 7 & 890 & 1030 & 1.135 & 0 & 1.243 & 128 & 1.361 & 1.408 \\
\hline $\begin{array}{l}\text { \% da Rec. Corrente } \\
\text { Educação }\end{array}$ & $70 \mathrm{~S}-2$ & 60 & $\%$ & $640 \%$ & $7,1 \%$ & $740 \%$ & $840 \%$ & 840 & $8,5 \%$ & $830 \%$ \\
\hline PIB & 3.110 & 3.333 & 3.886 & 4.376 & 4.815 & 5.332 & 5.779 & 5.996 & 6.259 & 6.560 \\
\hline$\%$ do PIB F & $1,1 \%$ & $1,3 \%$ & $1,5 \%$ & $1,5 \%$ & $1,7 \%$ & $1,7 \%$ & $1,8 \%$ & $1,8 \%$ & $1,9 \%$ & $1,8 \%$ \\
\hline
\end{tabular}

Fonte: TESOURO NACIONAL, 2018

Uma primeira análise do gasto total em educação, constante da primeira linha de dados da Tabela 1, permite concluir que houve um significativo aumento do total dos investimentos federais em educação, que saíram de R \$ 61,4 bilhões em 2008 para R \$ 117,2 bilhões em 2017, representando um aumento nominal de cerca de 90,8\%, percentual este superior inclusive à inflação acumulada do período que, segundo a variação do Índice Nacional de Preços ao Consumidor Amplo (IPCA), foi de $72,74 \%{ }^{4}$. Assim, houve um aumento real de investimentos federais em educação de $10,45 \%$ no decênio.

Entretanto, a variação do investimento em educação passou por dois movimentos: o primeiro, de progressivo crescimento, entre 2008 e 2014, seguido por um segundo período de redução do montante de investimentos, a partir de 2014 até 2017.

Percebe-se também que nos anos iniciais do período analisado o crescimento foi bem mais significativo que nos anos seguintes. Apenas de 2008 a 2010, os investimentos em educação provenientes do Orçamento da União foram de $\mathrm{R} \$ 61,4$ para $\mathrm{R} \$ 90$ bilhões, num aumento nominal de 46,57\%, sendo que a maior parte do valor acrescido foi destinado a investimentos em Educação Superior e Profissional.

Especificamente quanto aos investimentos em educação básica, os dados demonstram um panorama de variação semelhante ao do gasto total em educação, visto que seguia numa trajetória crescente até 2014 e partir daí sofreu reduções. Os investimentos da União em educação básica, que no início do período eram de R $\$ 18,9$ bilhões, chegaram em 2017 a $R$ \$34,6

\footnotetext{
${ }^{4}$ Valor obtido com base em cálculo dos dados disponibilizados pelo IBGE, entre Janeiro de 2008 e Dezembro de 2007. Disponível em https://www.ibge.gov.br/estatisticas/economicas/precos-e-custos/9256-indice-nacional-deprecos-ao-consumidor-amplo.html? =\&t=series-historicas. Acesso em 08 jul. 2019
} 
Revista da Faculdade Mineira de Direito |V.23 N.45 |

bilhões, registrando um aumento nominal de $83 \%$, sendo, portanto, um aumento mais tímido que o do total dos investimentos federais em educação.

Já em relação aos gastos da União com o ensino superior, houve uma ampliação bem mais significativa: os investimentos saíram de $\mathrm{R} \$ 31,8$ bilhões em 2008 para $\mathrm{R} \$ 75,4$ bilhões em 2017, registrando um aumento de mais de 137\% de recursos destinados a esse segmento, num nível de aumento superior inclusive à variação do PIB, que no mesmo período foi de 109,3\%.

Nota-se também que aumentou a distorção na proporção dos investimentos da União entre a educação básica e o ensino superior. Se em 2008 os investimentos no ensino superior eram 68,2\% maiores que na educação básica, tal superioridade passou a ser de 118\% em 2017.

A tabela a seguir permite compreender em que subáreas houve maior crescimento de aplicação de recursos da União:

Tabela 2

Taxas de crescimento nominal e real da despesa em educação (2008-2017)

\begin{tabular}{|c|c|c|}
\hline & $\begin{array}{l}\text { Variação nominal } \\
\text { 2008-2017 (\%a.a.) }\end{array}$ & $\begin{array}{c}\text { Variação real } \\
\text { 2008-2017 (\%a.a.) }\end{array}$ \\
\hline Educação & $14,3 \%$ & $7,4 \%$ \\
\hline Educação Superior e Profissional & $17,1 \%$ & $10,1 \%$ \\
\hline Institutos Federais de Ensino Superior & $11,4 \%$ & $4,7 \%$ \\
\hline Institutos Federais de Educação Tecnológica & $27,8 \%$ & $20,1 \%$ \\
\hline Hospitais Universitários & $40,6 \%$ & $32,1 \%$ \\
\hline Bolsas + Assistência ao Estudante & $24,2 \%$ & $16,7 \%$ \\
\hline FIES & $62,8 \%$ & $53,0 \%$ \\
\hline Educação Básica & $13,8 \%$ & $6,9 \%$ \\
\hline Fundeb + Salário Educação & $13,0 \%$ & $6,2 \%$ \\
\hline $\mathrm{PNAE}+\mathrm{DDE}+\mathrm{TE}+\mathrm{PNLD} *$ & $13,2 \%$ & $6,4 \%$ \\
\hline Outros & $1,5 \%$ & $-4,6 \%$ \\
\hline Pessoal & $6,8 \%$ & $0,4 \%$ \\
\hline Demais & $-1,7 \%$ & $-7,6 \%$ \\
\hline Receita Corrente - União & $7,2 \%$ & $0,7 \%$ \\
\hline PIB & $8,6 \%$ & $1,1 \%$ \\
\hline
\end{tabular}

Fonte: TESOURO NACIONAL, 2018

* Significado das siglas: Programa Nacional de Alimentação Escolar, Dinheiro Direto na Escola, TV Escola e Programa Nacional do Livro e do Material Didático.

Como se nota, o aumento da destinação de recursos pela União à educação básica, por meio do Fundeb, foi bem mais discreto que o acréscimo de verbas federais ao financiamento do ensino superior.

A observação das áreas de maior aumento demonstra que os governos do período, regra geral, deram especial atenção ao aparelhamento dos hospitais universitários e ao financiamento público de estudantes inseridos em instituições de ensino privado, tanto por meio de bolsas 
Revista da Faculdade Mineira de Direito |V.23 N.45 |

Programa Universidade Para Todos (Prouni) ${ }^{5}$ como através do Fundo de Financiamento Estudantil (FIES) ${ }^{6}$.

Assim, percebe-se que, apesar do gasto federal educacional ter crescido de forma significativa em todas as áreas nos últimos dez anos, a comparação do que foi destinado anualmente a cada área permite concluir que o governo federal não priorizou o aumento dos investimentos na educação básica, levando Estados e Municípios a assumirem a responsabilidade por sua oferta, e concentrando cada vez mais os seus recursos na educação superior e profissional.

\section{DISTORÇÕES NO REGIME DE FINANCIAMENTO E SUAS CONSEQUÊNCIAS}

\subsection{O aumento desproporcional de investimentos no ensino superior}

Como demonstrado nos dados apresentados, no período de 2008 a 2017 houve uma maior ampliação de investimentos da União no ensino superior que nos demais níveis de ensino. Todavia, a priorização de investimentos no terceiro grau da educação sem a garantia de um padrão mínimo de qualidade na educação básica pode trazer incongruências no sistema como um todo.

Nesse sentido, a Organização para a Cooperação e Desenvolvimento Econômico (OCDE), por meio do relatório "Um olhar sobre a educação" (OCDE, 2017), analisou comparativamente ${ }^{7}$ os sistemas educacionais de 46 países e mostrou que o Brasil é um dos países

\footnotetext{
${ }^{5}$ O Programa Universidade para Todos (ProUni), criado pela Medida Provisória no 213, de 13 de setembro de 2004, depois convertida na Lei 11.096, de 2005, é um programa criado pelo Ministério da Educação (MEC) que fornece bolsas de estudo parciais e integrais em instituições de ensino particulares, para estudantes de baixa renda, sem diploma de nível superior. A finalidade do projeto é ampliar o acesso à educação de nível superior para a população de baixa renda, através de bolsas de estudo de $50 \%$ (para estudantes de família com renda bruta per capita superior a 1,5 e inferior a 3 salários mínimos) ou 100\% (para estudantes de família com renda bruta per capita inferior a 1,5 salário mínimo). Podem participar do Prouni apenas os candidatos que se encaixam no perfil socioeconômico de baixa renda, público-alvo do programa, e alcancem uma nota mínima de 450 pontos em cada área do Exame Nacional do Ensino Médio, além de não zerarem a prova de redação.

6 O Fundo de Financiamento Estudantil (Fies) é um programa do MEC destinado a financiar a graduação na educação superior de estudantes matriculados em cursos superiores não gratuitas, na forma da Lei no $10.260 / 2001$, sendo operado atualmente pelo Fundo Nacional de Desenvolvimento da Educação (FNDE). Por se tratar de um sistema de financiamento, com taxa de juros de $6,5 \%$ ao ano, e não de concessão de bolsas sem contrapartida financeira, possui menor penetração entre estudantes de baixa renda e não possui as mesmas exigências de renda familiar per capita máxima, como o ProUni. Todavia, a exemplo do ProUni, também exige nota mínima de 450 pontos em cada área do Exame Nacional do Ensino Médio, além de não zerarem a prova de redação.

7 Nota: A metodologia de cálculo e comparação utilizada pela OCDE sobre as despesas com instituições educacionais como porcentagem do PIB em um determinado nível de educação são calculadas dividindo a despesa total por instituições de ensino a esse nível pelo PIB. Despesas e valores do PIB em moeda são convertidos em USD equivalente dividindo o valor da moeda nacional pela paridade do poder de compra (PPP) indexada para o PIB. Segundo a OCDE, o fator de conversão PPP é usado porque a taxa de câmbio do mercado é afetada por muitos
} 
Revista da Faculdade Mineira de Direito |V.23 N.45 |

que menos investe no ensino fundamental e médio. Entretanto, o país também apresenta um nível de despesa no ensino superior que se aproxima ao de países europeus.

Conforme aponta o referido relatório (OCDE, 2017), o Brasil gasta anualmente US \$3,8 mil por aluno da primeira fase do ensino fundamental (até a $5^{\text {a }}$ série), o que representa menos da metade da média de investimentos dos países OCDE nessa mesma fase.

Fenômeno semelhante se repete nos demais anos do ensino fundamental e no ensino médio. Segundo o relatório (OCDE, 2017), nessa etapa o Brasil gasta anualmente os mesmos US\$ 3,8 mil por aluno, valor bem inferior à média investida pelos países da OCDE na mesma fase, que é de US\$10,5 mil por aluno, o que corresponde a $176 \%$ a mais de recursos investidos que o Brasil.

O panorama se inverte quando se trata de investimentos no ensino superior. Nessa fase, o gasto por aluno passa para quase US\$11,7 mil, superando o triplo das despesas de cada uma das duas etapas anteriores, numa distribuição de recursos que destoa da tendência dos países membros da OCDE, que gastam quase a metade a mais por estudante do ensino universitário do que com os do primário.

Se o Brasil apresenta investimentos insuficientes na educação básica na comparação com os países da OCDE, em relação ao financiamento do ensino superior o Brasil se aproxima de países como Portugal, Estônia e Espanha, que investem, respectivamente, US\$11,8 mil, US\$ 12,3 mil e US\$ 12,5 mil, por aluno universitário a cada ano. Conforme aponta o relatório (OCDE, 2017), o Brasil gasta mais com os universitários do que países como Itália, República Checa e Polônia.

Os gastos brasileiros por aluno do ensino superior superam inclusive os da Coreia do Sul, país que está entre os primeiros colocados do Programa Internacional de Avaliação de Alunos (PISA) ${ }^{8}$ da OCDE e que investe anualmente U\$ 9,6 mil por universitário. Todavia, o país asiático investe montante superior no ensino fundamental (U\$9,7 mil), o que pode explicar seu melhor desempenho no programa citado.

A maior destinação de investimentos para o ensino superior no Brasil se torna ainda mais questionável diante de outro dado do relatório da OCDE: 52\% dos brasileiros entre 25 e 64 anos sequer chegam ao ensino médio (OCDE, 2017). O percentual corresponde a mais do que o dobro da média dos países da Organização e demonstra que maiores investimentos na educação

fatores (taxas de juros, políticas comerciais, expectativas de crescimento econômico, etc.) que pouco tem a ver com o poder de compra doméstico em diferentes países da OCDE.

${ }^{8}$ O Programa Internacional de Avaliação de Alunos (PISA) é um exame global, aplicado a cada três anos, que avalia o desempenho de estudantes na faixa dos 15 anos de idade em três grandes áreas do conhecimento: leitura, matemática e ciências. Seu objetivo é gerar indicadores que favoreçam a discussão e, consequentemente, a melhoria educacional do ensino básico nos países participantes. 
Revista da Faculdade Mineira de Direito |V.23 N.45 |

superior nem sempre atendem os fins que se esperam de uma política social e educacional, que é a redução da desigualdade social e a ampliação de oportunidades. Como lecionam Motta, Buíssa e Barbosa (2018, p. 110), as políticas públicas devem pautar-se na busca pela equidade, sendo pouco efetivas medidas de ordem geral que não levem conta a vulnerabilidade dos grupos mais carentes da população. Segundo tais autores, num ambiente de profunda desigualdade como o brasileiro, a ampliação do acesso ao ensino de qualidade é um dos pilares para a redução distorções sociais (BUISSA; MOTTA; BARBOSA, 2018).

A análise das despesas brasileiras em educação demonstra que quanto menos do Orçamento da União se investe em educação, menor é o acesso à educação básica, dada à grande dependência dos pequenos municípios dos repasses federais para financiarem suas escolas. Assim, repasses menores implicam em perda de qualidade de ensino e menor oferta de vagas. Conforme consta na Tabela 1 , as despesas federais em educação no Brasil deixaram de aumentar e passaram a diminuir a partir de 2014 e a diminuição se deu de maneira mais acentuada nos investimentos da educação básica, o que impactou diretamente no quantitativo de matrículas na fase final da educação básica, como mostra o gráfico a seguir.

\section{Gráfico 1}

Número de Matrículas no Ensino Médio (2008-2017)

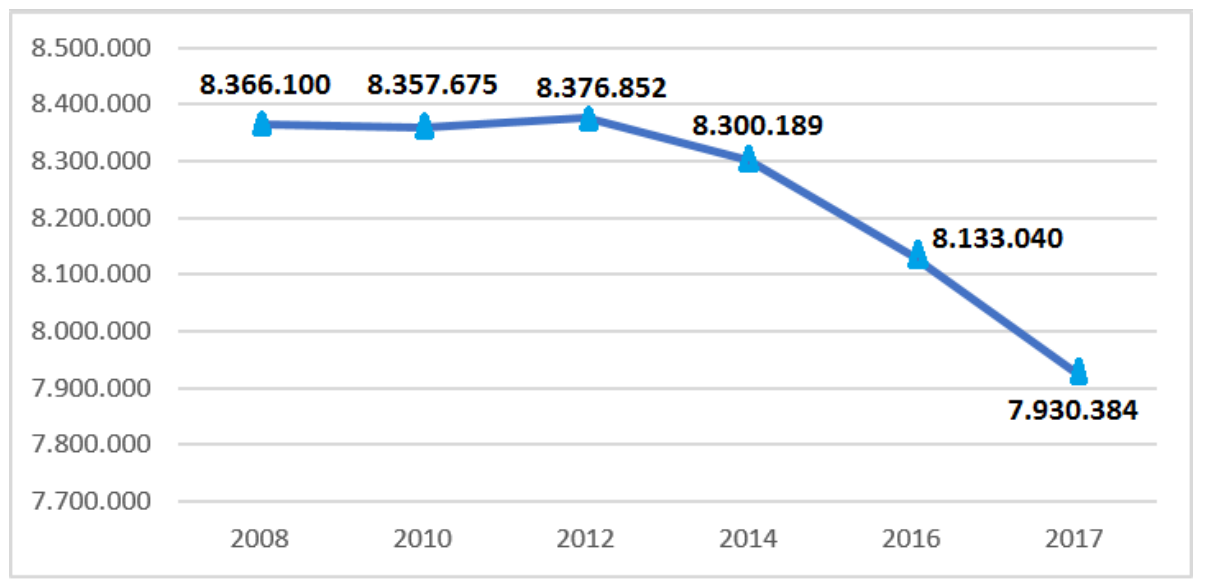

Fonte: INEP, 2018

Como se nota, o número de matrículas no Ensino Médio, que vinha se mantendo relativamente estável até 2014, com a redução dos investimentos federais passou a diminuir de maneira mais sensível. De acordo com dados do Anuário da Educação Básica 2018 (TODOS PELA EDUCAÇÃO, 2018), a taxa de evasão escolar no ensino médio vinha em queda até o levantamento de 2013/2014, tendência que foi interrompida em 2014/2015, com uma leve alta, fazendo com que a taxa de evasão chegasse a 11,2\% do total de alunos do Ensino Médio. Assim, 
Revista da Faculdade Mineira de Direito |V.23 N.45 |

anualmente, calcula-se que cerca de 1,7 milhão de pessoas entram na idade adulta sem ter completado o ensino médio e, destes, um milhão sequer concluiu o ensino fundamental (HELENE, 2013).

Ao contrário do fenômeno ocorrido no Ensino Médio no mesmo período, as matrículas no ensino superior cresceram entre 2008 e 2017, saindo de um total de 5.843 .322 em 2008 para 8.286.663 em 2017. Do total de 2017, 75,3\% das matrículas do ensino superior foram realizadas na rede privada (INEP, 2018).

Essa distorção aponta para o fato de que o crescimento do número de matrículas apenas no ensino superior não corrigiu desigualdades, visto que a redução de matrículas e o aumento da evasão do Ensino Médio contribui para que, mesmo com o aumento de matrículas nas universidades, continue sendo transportada a desigualdade da educação básica para o ensino superior. Conforme demonstra o Anuário da Educação Básica 2018 (TODOS PELA EDUCAÇÃO, 2018), mesmo com o avanço dos sistemas de bolsas, de financiamento educacional e de programas de ações afirmativas, no ano de 2017 apenas 7,2\% dos jovens de 18 a 24 anos integrantes da parcela de $25 \%$ mais pobre da população estava matriculada em cursos superiores (seja de graduação ou pós-graduação), percentual significativamente inferior aos 41,5\% dos alunos de mesma idade pertencentes ao quartil mais rico matriculados no mesmo nível educacional. No mesmo ano, havia sensível desigualdade também na comparação da taxa líquida de matrículas por cor de pele: enquanto $27,9 \%$ da parcela branca da população entre 18 e 24 anos estava matriculada no ensino superior, apenas 14,3\% dos jovens negros e 14,6\% dos pardos estava cursando ensino superior em 2017.

Percebe-se, portanto, que no Brasil há uma dupla desigualdade no acesso ao ensino superior: é significativamente mais difícil aos negros e pardos chegarem à universidade em relação aos de pele branca, sendo ainda mais difícil também ao pobre ingressar ao ensino superior em comparação aos ricos.

Ainda nesse sentido, o relatório "Um ajuste justo: análise da eficiência e equidade do gasto público no Brasil” (BANCO MUNDIAL, 2017), concluiu que apesar dos estudantes do ensino superior não pagarem por sua educação, mais de 65\% deles pertencem aos 40\% mais ricos da população, demonstrando que os gastos nestas universidades, diante da falta de equidade no acesso a elas, acaba funcionando como um subsídio regressivo em favor da parte mais rica da população brasileira.

Para a OCDE, a baixa escolaridade está ligada diretamente à má distribuição de renda. A entidade concluiu, no relatório "Um olhar sobre a educação" (OCDE, 2017), que "os países com menor proporção de pessoas com baixo nível educacional tendem a ter uma desigualdade de 
renda menor" (tradução nossa) ${ }^{9}$, que "o ensino médio se transformou num veículo de ascensão social ao mínimo exigido para a vida em uma sociedade moderna" (tradução nossa) ${ }^{10}$ e que "a desigualdade de renda é maior em países com alta parcela de pessoas sem ensino médio, como Brasil, Costa Rica e México, e menor em países com baixa proporção de pessoas sem ensino médio, como República Tcheca e Eslováquia” (tradução nossa). ${ }^{11}$

Se é verdade a ideia de que os investimentos públicos reduzem a desigualdade social, a concretização dessa máxima depende desses investimentos serem devidamente distribuídos, em sua maioria, à base do sistema educacional e não ao topo. É por isso que, no Relatório da OCDE para o Brasil (OCDE, 2018), a entidade recomendou maior atenção à educação básica, ressaltando o deslocamento de investimento para os níveis fundamental e médico elevariam a progressividade e a eficiência, visto que a oferta de educação pré-escolar tem o condão de reduzir a probabilidade de evasão de estudantes desfavorecidos do sistema de ensino.

Além da necessidade de melhor distribuição dos recursos do ensino superior aos outros graus de ensino, a própria forma de investimento na formação superior também merece reavaliação. Isso porque, conforme dados constantes da Tabela 2 , o governo federal tem aberto mão de investimentos em geração de vagas em instituições federais de ensino superior para, progressivamente, terceirizar a formação de graduados à iniciativa privada por meio de seus próprios recursos, através de bolsas e mecanismos de financiamento estudantil.

Especificamente no período analisado no presente estudo, o FIES apresentou amplo crescimento no número de contratos ativos, passando de 473.340 em 2008 para 2.185 .038 em 2015 (GILIOLI, 2017), correspondente a uma variação positiva de mais de 360\%.

Conforme destaca Renato Gilioli (2017), a maior variação positiva deste sistema de financiamento se explica em grande parte pela sua reformulação, ocorrida em 2007, que ampliou tanto o percentual de financiamento quanto os potenciais beneficiários, visto que nesse ano a Lei $n^{\circ} 11.552 / 2007$ possibilitou o financiamento de até $100 \%$ dos cursos e ampliou o benefício não apenas para estudantes de cursos superiores, mas também para a pós-graduação stricto sensu, que inclui mestrados e doutorados (GILIOLI, 2017).

Por sua vez, o ProUni também teve significativo crescimento, ainda que mais tímido que o do FIES, durante o período analisado, como mostra a tabela a seguir.

\footnotetext{
${ }^{9}$ Countries with a lower share of people with low educational attainment tend to enjoy lower income inequality.

${ }^{10}$ Upper secondary schooling has been transformed from a vehicle for upward social mobility into a minimum requirement for life in modern society.

11 Income inequality is largest in countries with a high share of people without upper secondary education, such as Brazil, Costa Rica and Mexico, and smallest in countries with a low share of people without upper secondary education, such as the Czech Republic and the Slovak Republic.
} 
Revista da Faculdade Mineira de Direito | V.23 N.45 |

Tabela 3

Quantidade de bolsas concedidas - ProUni (2008-2017)

\begin{tabular}{cccc}
\multirow{2}{*}{ Ano } & \multicolumn{3}{c}{ Quantidade de bolsas concedidas } \\
& Bolsas integrais & Bolsas parciais & Total de bolsas \\
2008 & 99.495 & 125.510 & 225.005 \\
2009 & 153.126 & 94.517 & 247.643 \\
2010 & 125.090 & 115.351 & 240.441 \\
2011 & 129.672 & 124.926 & 254.598 \\
2012 & 150.870 & 133.752 & 284.622 \\
2013 & 164.379 & 87.995 & 252.374 \\
2014 & 205.237 & 101.489 & 306.726 \\
2015 & 204.587 & 124.530 & 329.117 \\
2016 & 166.603 & 162.577 & 329.180 \\
2017 & 171.641 & 190.284 & 361.295 \\
\multicolumn{4}{r}{ Fonte: GILIOLI, 2017 }
\end{tabular}

Assim, conjugação destes dois sistemas federais de fomento ao ensino superior aos novos e crescentes sistemas de financiamento, tanto bancários quanto aos realizados pelas próprias universidades, além dos concedidos por outros entes da federação, proporcionou um relevante crescimento na criação de vagas em universidades privadas ao invés de fortalecer o sistema público de ensino.

\section{Gráfico 2}

Percentual de matrículas na rede privada brasileira com algum tipo de financiamento/bolsa (2009-2017)

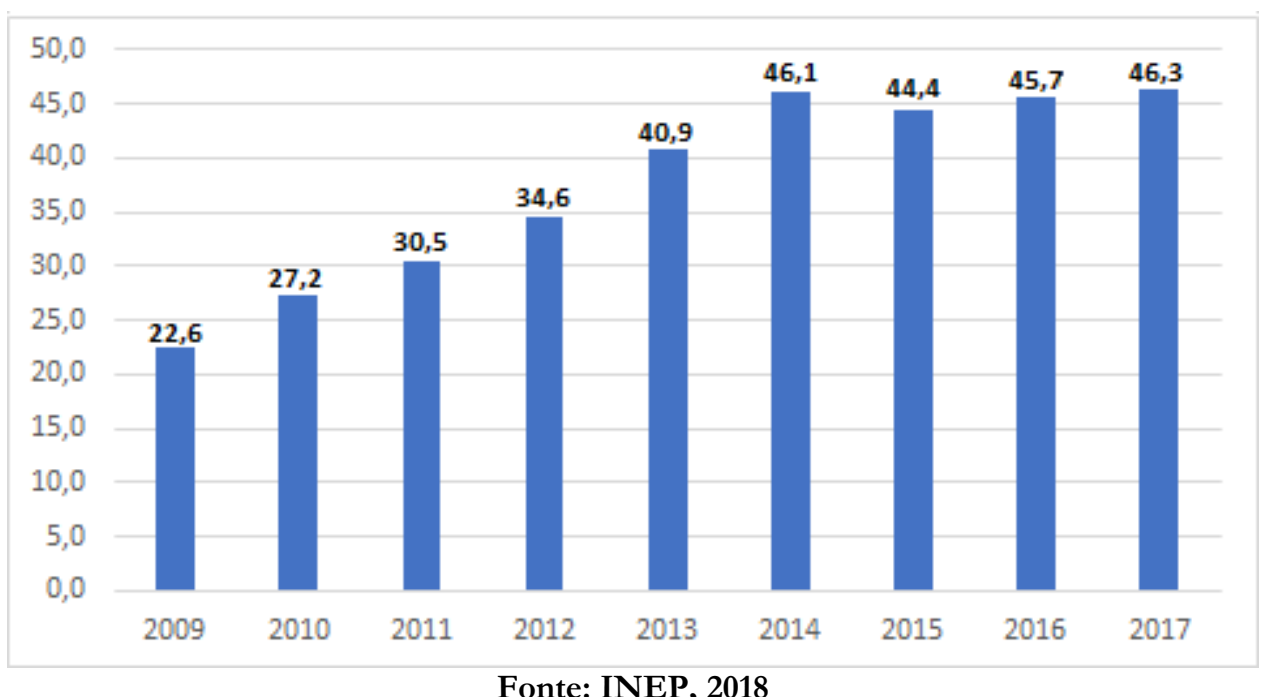

Fonte: INEP, 2018

Assim, essa política de expansão do acesso à educação superior, apesar de apresentar números crescentes e que demonstram ingresso de um número maior de alunos nas faculdades, não significou efetiva democratização no acesso, visto a ausência de igualdade nas condições de 
Revista da Faculdade Mineira de Direito |V.23 N.45 |

acesso a partir da educação básica e a fabricação de expansão apoiada em entidades com finalidade eminentemente lucrativa, num processo de massificação mercantilizadora que anula as fronteiras entre o público e o privado-mercantil e impede uma efetiva democratização do "subsistema” (SGUISSARDI, 2015).

\subsection{A Emenda Constitucional $\mathrm{n}^{\circ}$ 95/2016 e os reflexos da redução de investimentos em educação}

Outro fator de desequilíbrio no sistema de financiamento educacional no período de 2008 a 2017 foi a aprovação da Emenda Constitucional n 95/2016, que institui um Novo Regime Fiscal no âmbito dos Orçamentos Fiscal e da Seguridade Social da União.

A referida emenda promoveu um congelamento dos gastos públicos em saúde e educação, pelo prazo de 20 anos, por meio da limitação dos gastos dos Orçamentos Fiscal e da Seguridade Social da União ao valor referente à despesa primária realizada no exercício de 2016, corrigido em 7,2\% (sete inteiros e dois décimos por cento) para 2017 e, para os exercícios posteriores, ao valor do exercício imediatamente anterior, corrigido pela variação do Índice Nacional de Preços ao Consumidor Amplo - IPCA no período de doze meses encerrado em junho do exercício anterior a que se refere a lei orçamentária.

Essa emenda, ao alterar a vinculação entre receitas e despesas, afetou diretamente os gastos mínimos pelo Estado estabelecidos anteriormente na Constituição para as áreas da saúde e da educação, na medida em que, ao longo dos 20 anos posteriores à sua edição, quanto maior for o crescimento do PIB, maior será também será a redução real dos gastos em saúde e educação.

De acordo com o relatório "Um ajuste justo: análise da eficiência e equidade do gasto público no Brasil” (BANCO MUNDIAL, 2017), a implementação do teto de gastos da Emenda em questão exige a redução dos gastos em cerca de $0,6 \%$ do PIB ao ano em relação à tendência atual durante a próxima década, o que corresponde a um corte cumulativo de quase $25 \%$ nas despesas primárias federais (em proporção do PIB), o que reduziria o orçamento federal (também proporcionalmente ao PIB) aos níveis do princípio da década passada.

A análise dos gastos em educação, aqui apresentados, evidencia que já a partir de 2014, antes mesmo antes da promulgação da referida emenda, a educação já sofria cortes significativos de investimentos federais, que implicaram na redução deste tipo de despesa, real e nominalmente. Portanto, a referida alteração constitucional veio apenas para referendar constitucionalmente uma prática já adotada pela administração federal. 
Revista da Faculdade Mineira de Direito |V.23 N.45 |

Ademais, a limitação de gastos em educação ao crescimento da receita líquida de impostos vai de encontro ao compromisso constitucional de universalização do atendimento escolar, além de inviabilizar o alcance das metas do Plano Nacional de Educação 2014-2024 (Lei $\mathrm{n}^{\mathrm{o}}$ 13.005, de 25 de junho de 2014), incluindo a Meta $20^{12}$, que estabeleceu o objetivo para o país de investir o equivalente a $10 \%$ (dez por cento) do PIB até 2024, que evidentemente não será cumprido, visto que a tendência é que, na proporção com o PIB, os investimentos em educação passem a decrescer ao invés de aumentar.

Assim, a Emenda Constitucional no 95/2016 exime o Estado de cumprir seu dever de garantir uma educação que atenda a Constituição, e configura uma ofensiva conservadora de retirada de direitos sociais, tendo como alvo prioritário o projeto constituinte de 1988, que estabelece que o Estado deve intervir para a redução das severas desigualdades sociais e econômicas (MARIANO, 2017).

Além disso, a tal emenda compromete o atendimento ao direito fundamental à educação, elegendo-a como ponto de sacrifício para supostamente salvar o país da crise fiscal, em nome da incolumidade do atendimento às obrigações financeiras, colocando-as em posição de primazia diante do atendimento direitos sociais, que são os reais promotores do desenvolvimento e do real avanço socioeconômico do país. Como conclui Cynara Mariano (2017), a Emenda 95 fez uma opção equivocada ao visar alcançar superávit primário por meio do limite de gastos, o que contribui para aprofundar ainda mais a crise econômica para satisfazer setores ligados ao capitalismo rentista.

\subsection{A redução do aproveitamento dos impostos em educação.}

O financiamento público dos gastos estatais pode ocorrer por meio de diversas fontes de recursos, tanto tributárias quanto não tributárias. A primeira, de caráter impositivo, abrange impostos, taxas e contribuições sociais e econômicas, enquanto a segunda abrange a obtenção de recursos pelo Estado por outras formas, não compulsórias, a exemplo das operações de crédito e da emissão de títulos de dívida pública.

No caso da educação, de acordo com Jorge Abrahão de Castro, os recursos provenientes dos impostos são as principais fontes para os gastos, seguidos dos recursos do

\footnotetext{
12 Meta 20: ampliar o investimento público em educação pública de forma a atingir, no mínimo, o patamar de 7\% (sete por cento) do Produto Interno Bruto - PIB do País no $5^{\circ}$ (quinto) ano de vigência desta Lei e, no mínimo, o equivalente a $10 \%$ (dez por cento) do PIB ao final do decênio".
} 
salário-educação, sendo pouco relevantes aqueles provenientes das fontes não-tributárias. (CASTRO, 2007).

Por isso, diante do fato de que o financiamento das despesas educacionais ocorre quase que exclusivamente por meio de recursos tributários, torna-se importante a comparação entre a variação de gastos educacionais e evolução da carga tributária bruta.

\section{Gráfico 3}

Evolução da carga tributária bruta ${ }^{13}$ no Brasil - 2008-2017 (\% PIB)

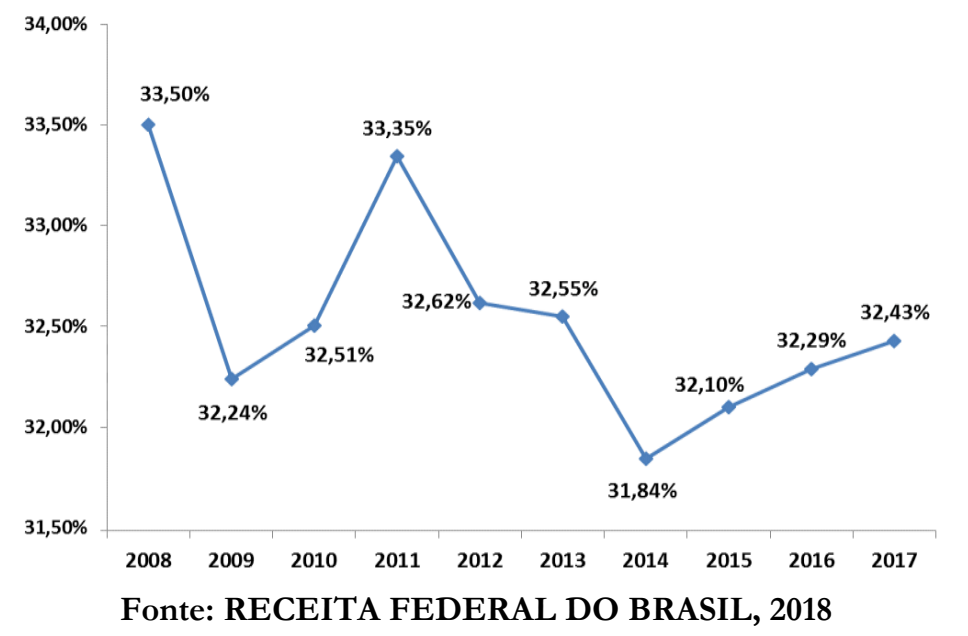

Nota-se que a carga tributária bruta brasileira variou, com altos e baixos a partir de 2008, até alcançar seu patamar mínimo em 2014, quando entrou em processo de crescimento relativamente constante.

No que tange à participação proporcional da União nessa arrecadação (que é foco desse estudo), houve uma pequena redução no período, com discreto crescimento de arrecadação dos Estados e Municípios:

Tabela 4

Evolução da participação dos entes federados na arrecadação total (\% PIB)

\begin{tabular}{l|cccccccccc} 
& $\mathbf{2 0 0 8}$ & $\mathbf{2 0 0 9}$ & $\mathbf{2 0 1 0}$ & $\mathbf{2 0 1 1}$ & $\mathbf{2 0 1 2}$ & $\mathbf{2 0 1 3}$ & $\mathbf{2 0 1 4}$ & $\mathbf{2 0 1 5}$ & $\mathbf{2 0 1 6}$ & $\mathbf{2 0 1 7}$ \\
\hline União & $69,37 \%$ & $68,80 \%$ & $69,01 \%$ & $69,98 \%$ & $69,05 \%$ & $68,93 \%$ & $68,46 \%$ & $68,32 \%$ & $68,37 \%$ & $68,02 \%$ \\
Estados & $25,47 \%$ & $25,73 \%$ & $25,47 \%$ & $24,49 \%$ & $25,16 \%$ & $25,29 \%$ & $25,47 \%$ & $25,45 \%$ & $25,45 \%$ & $25,72 \%$ \\
Municípios & $5,16 \%$ & $5,48 \%$ & $5,52 \%$ & $5,54 \%$ & $5,80 \%$ & $5,78 \%$ & $6,07 \%$ & $6,24 \%$ & $6,18 \%$ & $6,26 \%$ \\
\hline Total & $\mathbf{1 0 0} \%$ & $\mathbf{1 0 0 \%}$ & $\mathbf{1 0 0 \%}$ & $\mathbf{1 0 0 \%}$ & $\mathbf{1 0 0} \%$ & $\mathbf{1 0 0} \%$ & $\mathbf{1 0 0} \%$ & $\mathbf{1 0 0} \%$ & $\mathbf{1 0 0 \%}$ & $\mathbf{1 0 0} \%$
\end{tabular}

13 A Carga Tributária Bruta é definida como a razão entre a arrecadação de tributos e o PIB a preços de mercado, ambos considerados em termos nominais. 
Revista da Faculdade Mineira de Direito |V.23 N.45 |

Apesar da leve redução da participação da União no total arrecadado, ainda assim houve crescimento nominal da arrecadação tributária federal, conforme mostrado na Tabela 1 , que aponta significativo crescimento nominal do PIB entre 2008 e 2017. Na mesma Tabela, nota-se que se entre 2014 e 2017 houve redução nominal dos investimentos federais em educação de R\$ 130,2 para $\mathrm{R} \$ 117,2$ milhões $(11,1 \%$ ) e, no mesmo período, a receita corrente da União subiu de $\mathrm{R} \$ 1,243$ para $\mathrm{R} \$ 1,408$ bilhões (13,27\%) e o PIB aumentou de $\mathrm{R} \$ 5,779$ para $\mathrm{R} \$ 6.560$ bilhões $(13,5 \%)$. Isso demonstra que a redução dos investimentos em educação a partir de 2014 não foi simplesmente uma decorrência da queda de arrecadação tributária (que nominalmente sequer ocorreu) e sim em virtude da destinação de recursos para outras áreas.

Desse modo, o crescimento da carga tributária não resultou em aumento da aplicação em políticas públicas educacionais. Os gastos educacionais, assim, tem sofrido redução diante do déficit nas contas públicas federais, recorrentes desde 2014 e fruto da má gestão de recursos públicos, fazendo o cidadão brasileiro, ao mesmo tempo em que tem que gastar mais em tributos, paradoxalmente enfrente mais dificuldades no acesso e permanência na escola, como comprovaram os dados que mostram crescimento na evasão escolar a partir de 2014.

\subsection{A baixa eficiência do gasto público educacional brasileiro}

Não se pode negar que o Brasil avançou substancialmente no período de $2008 \mathrm{em}$ matéria de destinação de recursos para a educação. Tampouco o fato de que a melhoria do acesso à educação no referido período possibilitou a milhões de brasileiros conseguirem empregos melhores e um padrão de vida mais digno. Entretanto, além desse fenômeno ter cessado sua eficácia e passado a ocorrer redução de investimentos educacionais em nível federal a partir de 2014, há ainda o problema da ineficiência dos gastos educacionais no país, comprovado no fato de que a qualidade da educação permanece baixa quando comparada com outros países com níveis de investimento similares.

Tal fenômeno foi inclusive objeto de análise de relatório da OCDE (2018), que concluiu que o setor público brasileiro gasta 5,4\% do PIB em educação, acima da média dos países da OCDE e da América Latina. Por outro lado, países como Colômbia, o México e o Uruguai gastam menos por estudante do que o Brasil, mas apresentam desempenho superior nos testes PISA da OCDE, sugerindo que há espaço para melhorar a eficiência dos gastos (OCDE, 2018).

A ineficiência do modelo de financiamento da educação do país também foi objeto de críticas no relatório "Um ajuste justo: análise da eficiência e equidade do gasto público no Brasil" 
Revista da Faculdade Mineira de Direito |V.23 N.45 |

(BANCO MUNDIAL, 2017), produzido pelo Banco Mundial, que concluiu que as despesas brasileiras com ensino superior são ineficientes e regressivas e uma reforma no sistema de financiamento educacional poderia economizar até $0,5 \%$ do PIB do orçamento federal, visto que o Governo Federal gasta aproximadamente $0,7 \%$ do PIB com universidades federais e cerca de um quarto desse dinheiro é desperdiçado. Além disso, os gastos por aluno em universidades públicas são de duas a cinco vezes maiores que o gasto por aluno em universidade privadas, o que também aponta para a necessidade de maior eficiência na aplicação de recursos.

Some-se a isso o péssimo desempenho dos alunos brasileiros no PISA, em que o Brasil ocupa sempre as últimas posições. Em outro relatório do Banco Mundial (2018), produzido com base em dados do próprio PISA, concluiu-se que os estudantes brasileiros devem demorar mais de 260 anos para atingir o nível de proficiência na leitura dos alunos dos países ricos e 75 para atingir a pontuação média em matemática registrada pelos alunos dos países desenvolvidos, o que não só reforça a ineficiência do modelo educacional brasileiro como também demonstra o longo e difícil caminho para a melhoria dos padrões educacionais do país.

Assim, tudo o que foi exposto aponta para o fato de que gastos mais altos com educação não garantem qualidade, sendo fundamental a atenção à forma como o dinheiro é gasto. Como leciona Élida Graziane Pinto (2015), o mero atendimento matemático ao dever de gasto mínimo em educação não é suficiente se a ele corresponder regressividade imotivada de indicadores e índices oficiais de desempenho. Assim, gastar formalmente o montante mínimo de recursos vinculados, mas não assegurar o padrão de qualidade, é gastar mal e implica em lesão aos princípios da finalidade e eficiência (PINTO, 2015).

Como exposto ao longo do texto, um dos caminhos do financiamento da educação brasileira para se evitar o "gastar mal” a que a autora se refere é a realocação de gastos do ensino superior para os níveis médio, fundamental e educação infantil, para assim proporcionar maior inclusão. São os avanços feitos nos primeiros anos da educação que, segundo a OCDE (2018), resultam em melhor desempenho dos estudantes de famílias de baixa renda no ensino médio e, assim, podem viabilizar tão almejada equidade no acesso à formação superior.

\section{CONSIDERAÇÕES FINAIS}

A educação, diante de sua grande importância ao desenvolvimento do país, foi reconhecida na Constituição Federal de 1988 como um direito social cuja prestação é dever do Estado, que deve ampliar o acesso ao exercício desse direito de forma universalizada. Para tanto, foram estabelecidas a gratuidade do ensino público em estabelecimentos oficiais, a garantia de 
Revista da Faculdade Mineira de Direito |V.23 N.45 |

padrão de qualidade e a exigência de percentuais mínimos de investimento em educação pelos entes da federação.

Todavia, apesar da relativa ampliação de investimentos no período de 2008 a 2017 e da ampliação do acesso ao ensino superior, os indicadores mostraram que o financiamento federal da educação, apesar de apresentar um crescimento inicial superior inclusive ao do PIB, sofreu a partir de 2014 os efeitos do déficit nas contas públicas, tendo seu orçamento significativamente reduzido.

Viu-se também que esse processo de redução de verbas para a educação foi perenizado pelos próximos anos, por meio da EC 95/2016, que encarou a redução do orçamento social como uma das soluções para a crise econômica do país, o que remete ao que Naomi Klein chamou de capitalismo do desastre: a existência de crise econômica combinada à tomada de decisões que implicam verdadeira fraude aos interesses nacionais, numa agenda neoliberal que leva a cabo reformas em prol do livre mercado que, a longo prazo, só geram mais crises e aprofundamento ainda maior das desigualdades (KLEIN, 2008).

Além do problema da medida - de questionável constitucionalidade - de redução de recursos, o modelo educacional brasileiro padece de distorções, visto que não tem se mostrado eficaz no combate da desigualdade social, uma vez que o ensino não tem sido ofertado de forma equânime e as diferenças sociais não tem sido minimizadas.

Diante desse cenário, qualquer tipo de melhoria significativa depende de reassunção do Estado dos compromissos constitucionais estabelecidos pela Constituição, e da retomada da percepção do financiamento da educação como prioridade, na medida em que este tipo de investimento serve de instrumento de equalização e de caminho para o desenvolvimento, não devendo ser o primeiro alvo de cortes a cada sinal de crise.

Como já apontado em relatório do Banco Mundial (2017), um dos caminhos para a melhoria da qualidade das despesas públicas é a adoção de um rigoroso sistema de monitoramento e avaliação de políticas públicas, com foco em resultados e vinculação ao orçamento, o que pode subsidiar a escolha das soluções mais eficazes e que alcancem os objetivos constitucionais. Um dos desafios ao sucesso desse processo de monitoramento e avaliação é a quebra de restrições de acesso a informações sobre os gastos tributários e programas sociais, inclusive a pesquisadores de fora do governo, que é uma prática comum nos países da OCDE e que contribui significativamente para o aumento da eficiência e da responsabilidade do gestor público.

Outra importante medida, segundo a OCDE (2018), é a avaliação de experiências bemsucedidas de reformas no sistema de educação dentro do próprio país e a consideração sobre a 
Revista da Faculdade Mineira de Direito |V.23 N.45 |

expansão delas para o país. A entidade internacional cita o caso do Ceará, que combinando aumento de recursos com mecanismos de incentivo, estendeu a obrigação da criança de até nove anos estar matriculada na escola, instituiu avaliações periódicas dos alunos vinculadas a medidas de incentivo, estabeleceu o pagamento de profissionais da educação com base em desempenho e vinculou a repartição de receitas tributárias em maior volume aos municípios com melhores resultados escolares, o que incentivou a melhoria das escolas.

Assim, a ampliação de investimentos de forma eficiente, por meio de políticas públicas e com adequado planejamento, pode contribuir para a obtenção de avanços sociais conjugados com ganhos econômicos, e assim promover um duplo ganho: a prosperidade do indivíduo e o crescimento social e econômico do país por meio da educação.

\section{REFERÊNCIAS}

BANCO MUNDIAL. Um ajuste justo: análise da eficiência e equidade do gasto público no Brasil. Novembro, 2017. Disponível em:

$<$ http://documents.worldbank.org/curated/en/884871511196609355/pdf/121480-REVISEDPORTUGUESE-Brazil-Public-Expenditure-Review-Overview-Portuguese-Final-revised.pdf $>$. Acesso em 11 jul. 2019.

BANCO MUNDIAL. World Development Report 2018: Learning to Realize Education's Promise. Washington: Banco Mundial, 240 p., 2018. Disponível em < https://www.worldbank.org/en/publication/wdr2018>. Acesso em 11 jul. 2019.

BRASIL. Constituição da República Federativa do Brasil (1988). Disponível em: $<$ http://www.planalto.gov.br/ccivil 03/Constituicao/ConstituicaoCompilado.htm>. Acesso em 04 jul. 2019.

BRASIL. Emenda Constitucional no 95, de 15 de dezembro de 2016. Diário Oficial da República Federativa do Brasil. Brasília. 15 dez. 2016. Disponível em: < http://www.planalto.gov.br/ccivil 03/constituicao/Emendas/Emc/emc95.htm >. Acesso em: 11 jul. 2019.

BRASIL. Lei 13.005, de 25 de junho de 2014. Aprova o Plano Nacional de Educação - PNE e dá outras providências. Disponível em:

< http://http://presrepublica.jusbrasil.com.br/legislacao/125099097/lei-13005-14>. Acesso em: 12 jul. 2019.

BRASIL. Programa Universidade para Todos (Prouni). Dados e estatísticas. Disponível em: $<$ http://prouniportal.mec.gov.br/dados-e-estatisticas/9-quadros-informativos $>$. Acesso em: 10 jul. 2019.

BUCCI, Maria Paula Dallari; MELLO, Paula Branco de. Democratização e acesso à educação superior - Parte I. Grupo Estratégico de Análise da Educação Superior no Brasil, realizado pela FLACSO-Brasil, com apoio da Fundação Ford, Rio de Janeiro, 2013. Disponível em http://flacso.org.br/?publication=opiniao-n7-democratizacao-e-acesso-a-educacao-superiorparte-i. Acesso em 14 jul. 2019. 
Revista da Faculdade Mineira de Direito |V.23 N.45 |

BUISSA, Leonardo; MOTTA, Fabrício; BARBOSA, Maísa. O financiamento da educação no Brasil como instrumento de aprofundamento da desigualdade social. A\&C - Revista de Direito Administrativo \& Constitucional, v. 18, p. 97-114, 2018.

CASTRO, Jorge Abrahão de. Financiamento e gasto público na educação básico no Brasil: 1995 a 2005. Educação \& Sociedade, Campinas, vol. 28, n. 100 - Especial, p. 857-876, out. 2007.

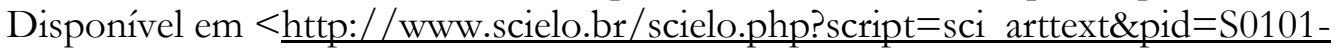
73302007000300011>. Acesso em 16 jul. 2019.

GILIOLI, Renato de Sousa Porto. Um balanço do Fies: desafios, perspectivas e metas do PNE. In: Ana Valeska Amaral Gomes. (Org.). Plano Nacional de Educação: olhares sobre o andamento das metas. 1ed. Brasília: Edições Câmara (Câmara dos Deputados), 2017, v. -, p. 195226. Disponível em < $\underline{\text { https://www2.camara.leg.br/atividade-legislativa/estudos-e-notas- }}$ tecnicas/publicacoes-da-consultoria-legislativa/areas-da-conle/tema11/um-balanco-do-fiesdesafios-perspectivas-e-metas-do-pne>. Acesso em 16 jul. 2019.

HELENE, Otaviano. Um diagnóstico da educação brasileira e de seu financiamento. Campinas: Autores Associados, Campinas-SP, 2013.

INSTITUTO NACIONAL DE PESQUISAS EDUCACIONAIS ANÍSIO TEIXEIRA (INEP). Censo da Educação Superior 2017. Set. 2018. Brasília. Disponível em <

http://download.inep.gov.br/educacao superior/censo superior/documentos/2018/censo da educacao superior 2017-notas estatisticas2.pdf $>$. Acesso em 10 jul. 2019.

KLEIN, Naomi. A doutrina do choque: a ascensão do capitalismo de desastre. Trad. Vania Cury. Rio de Janeiro: Nova Fronteira, 2008.

MARIANO, Cynara Monteiro. Emenda constitucional 95/2016 e o teto dos gatos públicos: Brasil de volta ao estado de exceção econômico e ao capitalismo do desastre. Revista de Investigações Constitucionais, Curitiba, vol. 4, n. 1, p. 259-281, jan./abr. 2017. Disponível em < https://revistas.ufpr.br/rinc/article/view/50289>. Acesso em 13 jul. 2019.

ORGANIZATION FOR ECONOMIC CO-OPERATION AND DEVELOPMENT - OECD (2018). Relatórios Econômicos OCDE: Brasil 2018, Éditions OCDE, Paris. 2018. p. 119.

Disponível em < https://epge.fgv.br/conferencias/apresentacao-do-relatorio-da-ocde2018/files/relatorios-economicos-ocde-brasil-2018.pdf>. Acesso em 12 jul. 2019.

ORGANIZATION FOR ECONOMIC CO-OPERATION AND DEVELOPMENT - OECD (2018). Education at a Glance 2017: OECD indicators. Paris. OECD Publishing, 2017.

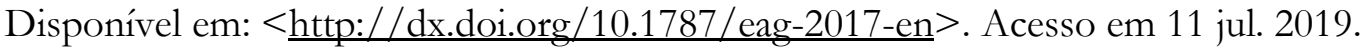

PINTO, Élida Graziane. Financiamento dos Direitos à Saúde e à Educação. Belo Horizonte: Fórum, 2015.

RECEITA FEDERAL DO BRASIL. Carga Tributária no Brasil 2017 - Análise por Tributos e Bases de Incidência. Nov. 2018. Disponível em:

$<\underline{\text { http://receita.economia.gov.br/dados/receitadata/estudos-e-tributarios-e-aduaneiros/estudos- }}$ e-estatisticas/carga-tributaria-no-brasil/carga-tributaria-2017.pdf $>$. Acesso em 09 jul. 2019. 
SGUISSARDI, Valdemar. Educação Superior no Brasil: Democratização ou massificação mercantil?. Educação \& Sociedade [online]. 2015, vol.36, n.133, pp.867-889. ISSN 0101-7330. Disponível em $<$ http://www.scielo.br/scielo.php?script=sci arttext\&pid=S010173302015000400867>. Acesso em 15 jul. 2019.

TESOURO NACIONAL. Aspectos Fiscais da Educação no Brasil, 2018. Disponível em $<$ http://www.tesouro.fazenda.gov.br/documents/10180/617267/CesefEducacao9jul18/4af4a6 db-8ec6-4cb5-8401-7c6f0abf6340>. Acesso em 07 jul. 2019.

TODOS PELA EDUCAÇÃO. Anuário Brasileiro da Educação Básica. Organizado por Priscila Cruz e Luciano Monteiro. São Paulo: Moderna, 2018. Disponível em $<$ https://todospelaeducacao.org.br/conteudo/anuario-brasileiro-da-educacao-basica-2018disponivel-download $>$. Acesso em 10 jul. 2019. 